\title{
El pensamiento liberal y anticlerical del siglo XIX, analizado en la obra de Jeffrey Klaiber S.J.
}

\section{The liberal and anticlerical thought of the $19^{\text {th }}$ century, analyzed in the Jeffrey Klaiber S.J. writings}

Fernando Armas Asín ${ }^{1}$

Universidad del Pacífico

\section{Resumen}

A partir de entender las limitaciones que la historiografía tradicional ha tenido en el estudio del anticlericalismo, el texto explora los aportes del padre Jeffrey Klaiber para su comprensión, concluyendo que sus investigaciones ayudaron a una mejor conceptualización del fenómeno, planteando líneas novedosas para el entendimiento del fenómeno al futuro. Este texto puede servir para un mejor conocimiento de la historiografía sobre el anticlericalismo peruano del siglo XIX.

Palabras Claves: Anticlericalismo, Estado, Iglesia, Liberalismo, Perú.

1 Doctor en Filosofía y Letras (Historia) (Universidad de Navarra). Código ORCID: 0000-0001-7050-1423 Contacto: Armas_fa@up.edu.pe 


\section{Abstract}

From understanding the limitations that the traditional historiography has had in the anti-clericalism study, the text explores the contributions of father Jeffrey Klaiber for its comprehension, concluding that their investigations helped in a better conceptualization of the phenomenon, proposing new lines for the understanding of the phenomenon in the future. This text can help to get a better historiographic knowledge of the Peruvian anti-clericalism of the $19^{\text {th }}$ century.

Keywords: Anti-clericalism, State, Church, Liberalism, Peru

En la obra y reflexiones del padre Jeffrey Klaiber S.J. el pensamiento liberal tiene un lugar destacable, particularmente el del siglo XIX. Por extensión su interés por el anticlericalismo liberal también, en la medida que le ayudó a entender a este pensamiento moderno en su relación con el campo religioso y en particular con una institución como lo es la Iglesia Católica.

El anticlericalismo poco se ha estudiado en nuestro medio, y peor aún, todavía se le entiende mal. De allí la raíz de su importancia, a nuestro entender. El anticlericalismo moderno surge en la praxis y la teoría de fines del siglo XVIII en Europa, aunque en América Latina no se desarrolla sino

170 hasta el siglo XIX, tomando ribetes especiales según las circunstancias locales en México, Colombia o Argentina, casos bastantes estudiados. La crítica al clero -o a la institución eclesial- es un rasgo esencial del anticlericalismo, presionando a su reforma, pero también por su destrucción y acaso su sustitución en los roles y estatus desempeñados. Lo cual podría o no estar acompañado de la crítica al sistema de ideas que la sostiene, la religión (Bada Elías, 2002; Di Stefano, 
2010; Rémond, 1983). La complejidad del fenómeno, cuyas aristas conceptuales las ciencias sociales han tardado en delimitar explica también las imprecisiones o consideraciones que entre los historiadores locales ha tenido lugar.

Visto así, en las siguientes páginas vamos a estudiar la aproximación que el padre Klaiber tuvo sobre el anticlericalismo del siglo XIX en el Perú. Nuestro interés es revisar como lo concibió, las relaciones que estableció entre el anticlericalismo y el campo religioso, así como la valoración que tuvo sobre el mismo. Nuestra hipótesis es que contribuyó a una delimitación de este fenómeno social, conceptualizándolo de manera novedosa, pero mostrando algunos límites en la relación que estableció con el campo religioso, debido a la fuerte influencia en el medio historiográfico local de una perspectiva tradicional sobre el fenómeno.

Para desarrollar este planteamiento analizaremos dos textos esenciales suyos. Nuestro orden de desarrollo es el siguiente: primero estableceremos cuál era el estado previo de la historiografía eclesiástica local frente al liberalismo y el anticlericalismo peruanos; luego revisaremos cómo concibió Klaiber al liberalismo; para luego establecer los parámetros en los que entendió al anticlericalismo, su relación con la religión, y la transformación o no de perspectiva que tuvo en estas aproximaciones. Finalmente concluiremos, mostrando los principales resultados del análisis efectuado.

\section{La impronta de la historiografía eclesial en torno al liberalismo}

Como bien sabemos en Europa y América el siglo XIX estuvo marcado por un lento proceso de secularización social, económica y cultural que, aunque iniciada tiempo atrás, se profundizó, acompañado de un proceso de laicización del 
Estado. Las dinámicas fueron, por cierto, diversas según regiones y países, pero en general en nuestro ámbito ello significó un conglomerado de reformas que a lo largo del siglo XIX e inicios del siglo XX se implementaron, de orden legal básicamente, que configuraron algunos cambios en las relaciones entre el Estado y la Iglesia, y del rol de ésta en la sociedad (Armas Asín, 2010; Cárdenas, 2007; García Jordán, 1993; Mauro y Martínez, 2015; Rémond, 2001; Tschannnen, 2001).

El liberalismo, en formación, portador fundamental de esta corriente de transformación, tuvo entre sus pensadores locales a diversos nombres; existiendo también entre ellos, con los ańos, algunos que cuestionaron a la institución eclesial y a la religión en la sociedad. Este pensamiento anticlerical y antirreligioso sin embargo fue sólo una arista del pensamiento liberal o de otras corrientes reflexivas modernas más amplias, igualmente en pleno desarrollo conceptual.

La discusión legal y social que generó el proceso de secularización del siglo XIX ocasionó diversas reacciones, primero de los sectores eclesiásticos e intelectuales favorecedores de la preservación de las viejas maneras de comprender la religión y la Iglesia en la sociedad -en condiciones de Antiguo Régimen-; y luego del clero romanista y conservador que se fue formando en la primera mitad de aquél siglo, dentro de un proceso reactivo eclesial ante los cambios acelerados del mundo moderno (Alberigo, 2004; Aubert et. al., 1984;

172 Lortz, 2003). Por supuesto el fenómeno fue europeo, pero también fue latinoamericano, desarrollando determinadas coordenadas y condicionantes (De Roux, 2014; Martínez, 2014).

En ese contexto la historiografía sobre la Iglesia Católica, producida por eclesiásticos, hasta mediados del siglo XX, fue producto de esa lucha intensa antiliberal y es rastreable 
en figuras como Rubén Vargas Ugarte, quien en sus múltiples obras, y particularmente en la Historia de la Iglesia en el Perú (1953-1962), rechazó lo que a su parecer eran intromisiones del Estado sobre la Iglesia, algo no deseable -desde una óptica romanista y contemporánea, ajena a una realidad de siglos en sentido muchas veces contrario- denunciando también el creciente carácter laicista y antirreligioso en el Perú en el transcurso del siglo XIX, y señalando de "antirreligiosos" a Francisco Javier Mariátegui, Benito Laso, Francisco de Paula Gonzáles Vigil, José Gálvez o José Gregorio Paredes; además de "soberbio" a Vigil (Vargas Ugarte, 1962, V: pp. 226 y 235). Antonine Tibesar OFM continuó dicha perspectiva, y en varios trabajos, y en particular en uno sobre la reforma de regulares (1826), señaló al Estado de entrometerse en la Iglesia y la vida religiosa, de ser parte de un plan general de secularización social del mundo, y finalmente de ser planeada esta medida por clérigos extranjeros, un general boliviano (Andrés de Santa Cruz) y cincuentaisiete afrancesados limeńos reputados por blancos (Tibesar, 1982, pp. 205-239). Otros trabajos suyos denotaron igual cariz frente al liberalismo peruano y el proceso secularizador en general.

\section{Jeffrey Klaiber S.J.: Liberalismo, religión y cambio social}

Justamente cierta influencia inicial de Antonine Tibesar O.F.M. y de Rubén Vargas Ugarte S.J. se puede apreciar en la tesis doctoral de Jeffrey Klaiber, dirigida por el primero, publicada en Estados Unidos en 1977 y en el Perú en 1980, bajo el título de Religión y Revolución en el Perú, 1824-1976. En ella nuestro autor hace conocer sus propios puntos de vista respecto del liberalismo de inicios del siglo XIX y sobre la figura de Manuel Gonzáles Prada y otros, a fines de ese siglo, ideas planteadas claramente en los dos primeros capítulos y parte del cuarto. 
En el primero, titulado "El Gran Templo de la Ley. Los orígenes del anticlericalismo en el siglo XIX”, remarca que no se ha prestado mucha atención a la actitud liberal para con la Iglesia como institución, sus ideas sobre la religión y su papel en la sociedad. Por ello, para desarrollar su apreciación, se apoya en Karl Mannheim y distingue entre ideología, como sistema de ideas que favorece el estatus quo; y utopía, como idea y actitud que favorecen el cambio. Bajo esa premisa trata de probar que los liberales quisieron el establecimiento de un orden legal republicano, pero no el cambio social posterior, y que ello los llevó a no valorar a la Iglesia como agente de cambio (Klaiber, 1980, pp. 23-24).

En esa perspectiva piensa que los liberales, que estuvieron interesados en asuntos eclesiásticos, ganaron diversas batallas a lo largo del siglo como la reforma de regulares (1826), la supresión de fueros y diezmos a mediados de siglo, pero en el congreso de 1867, "nuevas propuestas anticlericales" fueron rechazadas, como la tolerancia de cultos, denotando una limitación en el avance de sus reformas, por las propias otras fuerzas políticas que no estuvieron dispuestos a tanto (Klaiber, 1980, p. 25). Y es que recuerda que, los llamados liberales anticlericales, no tuvieron mucha aceptación en la sociedad en parte por la fuerza de la cultura y tradición hispánicas en las clases altas y en parte por el catolicismo arraigado en las clases altas (Klaiber, 1980, p. 24).

Sobre la base de los estudios existentes subraya que estos liberales se basaban en ideas galicanas y jansenistas -propias del siglo XVIII y del contexto europeo y americano-, que planteaban la necesidad de una Iglesia nacional, sobre la base de la autonomía de los obispos respecto al Papa, y la urgencia de una reforma eclesiástica para consolidar una iglesia auténticamente evangélica. Y que, además, así como en el pasado borbónico, al ser conscientes de la importancia de la Iglesia como institución influyente en la esfera social y ser un apa- 
rato burocrático con llegada al amplio espectro territorial, les interesó asegurar su dominio y sujeción al Estado liberal, siendo de esta manera herederos del regalismo dieciochesco. Pero como buenos cristianos creyeron en la religión en general y la Iglesia Católica en particular, como base para asegurar una sociedad ordenada -por ello rechazaron el ateísmo, como fue el caso de Manuel Lorenzo Vidaurre-. Aunque su apreciación es que todos estos desarrollos se enmarcaron en un orden liberal legal, desde el cual esperaban conseguir la ansiada felicidad social.

Ideas similares lo sostuvo años después, en La Iglesia en el Perú (1988), donde subrayó que los liberales sólo buscaron propender a una sociedad democrática e igualitaria sobre la base de las leyes, pues no tenían un concepto amplio del cambio social y además poseían poco contacto con las clases populares (Klaiber, 1988, p. 97). Esta aseveración al parecer proviene en general de Jorge Basadre, al cual valora como quien mejor entendió el desempeño del liberalismo peruano, y que planteó que solo buscaron un cambio de la sociedad a través de las ideas (Klaiber, 1980, p. 39).

Visto en retrospectiva el cambio social para el liberalismo inicial peruano se había dado con la independencia en la esfera política y la transformación social sería obra de la racionalidad humana, cuya mejor plasmación se daría a través de la conciencia legal. Era coherente meridianamente con la perspectiva de su tiempo, y le era ajena la idea del cambio social permanente, hija del desarrollo de las ciencias sociales que recién tomó cuerpo a mediados del siglo, y ajena al propio desempeño social del grupo. En esa lógica no valoraron al cuerpo eclesial de su tiempo como agente de cambio pues lo consideraban como un aparato propio del antiguo régimen que precisamente lo impedía. 
Klaiber les reconoce haber sentado los cimientos de la República, y en el largo plazo conseguir que sus ideas penetren en los "movimientos reformistas posteriores" (Klaiber, 1980, p. 25). Pero, en su tesis doctoral añadió una idea mayor: valoró como "liberales anticlericales" a los jansenistas, galicanos y regalistas de los primeros años republicanos -como Vidaurre, Vigil y Mariátegui-. Veamos sus razones y el matiz posterior en su parecer.

\section{Los liberales regalistas, jansenistas y galicanos vistos como anticlericales}

Al referirse a Manuel Lorenzo Vidaurre, planteó que su visión sobre la religión permite apreciar su crisis personal pero también la crisis transicional del Perú, al buscar conciliar su fe con la nación en construcción. En el Plan del Perú (1823) y el Proyecto de Código Eclesiástico (1830) se pueden ver sus ideas galicanas y jansenistas en pro de una iglesia nacional, reformada y en espíritu evangélico, aunque también en el Plan de Perú considera que el catolicismo es esencial en la sociedad y el Papa es su guía; además que en el Proyecto de Código Penal (1828) considera delitos contra la religión las blasfemia, la herejía y el ateísmo, pero aceptando la tolerancia entre cristianos. Así pues plantea a la religión como la base del orden y el gobierno, y ayuda al desarrollo de los pueblos. El problema son los malos sacerdotes, y por ello la necesidad de la reforma. Perspectiva jansenista que insistirá en Vidaurre contra Vidaurre (1839) donde reivindica a la religión y al Papa, pero rechaza claramente el creciente ultramontanismo dentro del clero y aboga por la sujeción del romano pontífice a los concilios (Klaiber, 1980, pp. 26-30).

Sobre Francisco de Paula Gonzáles Vigil argumenta que causó más preocupación en los eclesiásticos que las actitudes de 
Vidaurre, por sus enfáticas ideas galicanas y regalistas, aunque reconoce que no planteó la supresión del papado sino más bien el combate a la curia romana por querer unir lo temporal y espiritual en su figura. Luchó por la devolución de un papado e iglesia a un ámbito exclusivamente espiritual; a nivel local por una iglesia nacional con obispos y sacerdotes dedicados a la labor pastoral; y regalistamente un Estado vigilante de tal rol. Sus ideas no solo fueron coherentes con el galicanismo y jansenismo -plasmadas en la Defensa de la autoridad de los gobiernos y de los obispos contra las pretensiones de la curia romana (1848-49)- si no además compatibles con el pensamiento liberal en formación, en la medida que distinguió claramente la separación de planos -temporal y espiritual-.

Con mucha lucidez Klaiber analiza que este Vigil, mal presentado por los eclesiásticos como un lobo feroz, renovó una idea común en su generación: el creer que la religión es la base de una sociedad estable, elemento de orden, justicia y amor, y por lo mismo que debe ser protegida por el Estado. Así, aboga, en su sexta disertación de la Defensa o en el inédito trabajo Religión Natural, que gracias a la conciencia se conoce el orden moral, por lo que este estado individual debe ser protegido por el Estado, salvo que contravenga los derechos de los demás y el fin común. Amparado en ello se debe respetar a todas las creencias ancladas en el evangelio, salvo las sectas y ateos, y de allí su defensa de la tolerancia religiosa, y su actitud de considerar que sólo los individuos y no el Estado deben tener religión, abogando también por una religión natural. Como se ve, síntesis de ideas propias de fines del siglo XVIII y de inicios del siglo XIX, en Europa y América. A tono con los tiempos abogó Vigil, para lograr el progreso de los pueblos, por la educación popular tanto como por la migración de extranjeros, que se constituyó en un argumento adicional para la tolerancia. 
Sin embargo, Klaiber también critica a Vigil al considerarlo como "inconsecuente", debido a que vio en sus ideas de separación entre los poderes temporales y civiles contradicción con su idea de valorar el rol interventor del Estado para lograr la reforma de la Iglesia (Klaiber, 1980, p. 32). Esa relación era aceptable para el pensamiento de la época, que consideraba no sólo un deber del Estado allanar el camino hacia una sociedad natural sino además percibía al Estado -recuérdese la teoría sobre el Estado en la filosofía política de la época- como el único instrumento con poder para oponerse a la curia romana. Compartía Vigil tal visión con la generación de pensadores liberales de la época.

Finalmente, sobre Francisco Javier Mariátegui, resalta que tuvo muchas coincidencias en materia religiosa con Vigil, aunque también tuvo apreciaciones algo distintas, por ejemplo, en cuanto al Papa. Refiere su trascendencia regalista, como sus ideas sobre la religión natural y la necesidad de la reforma religiosa para devolverle a la iglesia su espíritu evangélico. Lo cuál lo unió a los pensadores ya revisados, así como a Benito Laso o Mariano Amézaga (Klaiber, 1980, pp. 38-39).

El aporte de Jeffrey Klaiber a la mejor comprensión de estos tres pensadores es necesario de remarcar. Los analizó integralmente en sus ideas e influencia social. Además, como un historiador interesado en el presente le interesó, rescatar aspectos que a su parecer fueron positivos o negativos de la acción de estos liberales. Así consideró oportuno que distinguieran entre la Iglesia primitiva evangélica y la que luego se instituyó con los siglos -criticable esta última por su pompa y descuido de las esencias espirituales y pastorales- y se buscara de manera permanente el regreso a la primera. Dado su interés por apoyar el desarrollo de una Iglesia al servicio de los pobres y con rostro social en el siglo XX, para Klaiber esta acción resultó valiosa. También avaló la distinción entre la 
religión que puede propalar una institución y el instinto religioso social de las personas, que no necesariamente coincide (Klaiber, 1980, p. 40). Es una crítica que le permite alejarse de una religión institucionalizada que impide ir en pos de una religión producida constantemente desde la sociedad.

Pero le cuestionó al liberalismo que buscase una Iglesia circunscrita al ámbito espiritual solamente, una Iglesia que no debiera opinar sobre política - presente en Mariátegui y sus ideas, por ejemplo-, que refuerce además el orden republicano naciente (Klaiber, 1980, pp. 40-41). Visto hoy, se trataba por cierto de convertir a un cuerpo eclesial de antiguo régimen en una institución al servicio del orden republicano, signado por ser el camino a la felicidad y el bienestar. Que no cumpliera un rol político público era entendible dado el peligro que representaba en ese proceso de transito -la idea de la domesticación moderna del cuerpo religioso-, y porque para ese rol estaban teóricamente en sus mentes otras instituciones - recuérdese que estamos ante una construcción de un pensamiento y sociedad democráticas, y los lugares dentro de la esfera pública son objeto de constantes disputas-. Hay un ideal liberal que no ha conocido todavía la crítica a su propia razón de ser y de la sociedad; como ciertamente también los conservadores romanistas, que igual tienen un ideal estrecho de los roles institucionales.

Klaiber no les da tregua: "Vidaurre, con su piedad pomposa; Vigil, con su asalto enciclopédico contra las pretensiones curialistas; y Mariátegui con sus admoniciones estridentes contra concordatos papales; todos lucharon por un liberalismo que presumía que la religión es el siervo del orden" (Klaiber, 1980, p. 41).

La critica al ideal regalista de una institución -cuerpo eclesial se entiende- que pase de mantener el viejo estatus quo a sostener el nuevo, y no sea autónoma, es central. Como también 
lo es que no la valoren como una institución que busque un cambio social constante. Habrá que afirmar que no se planteaban que el orden republicano en sí deviniese en oprobioso pronto y por ello no fuera garantía de prosperidad, aunque es cierto que las teorías sobre el cambio social constante no estaban incorporadas en sus pensamientos. Esto último es exigible al liberalismo peruano, por lo menos al tardío Mariátegui (del Manual del Regalista, 1873), que no incorpora las nuevas miradas del pensamiento moderno de mediados de siglo.

Aparte de esto también les arrostra no haber comprendido a la religiosidad popular, a la cual además menosprecian, y tampoco que los problemas del país tendrían causas más profundas. "...en su concepto del elemento religioso en el hombre y la sociedad, y en su comprensión del papel de la religión entre las clases populares... no eran sino estudiantes cautivos de enciclopedias polvorientas" (Klaiber, 1980, p. 42). Para una sociedad que compartía acríticamente en sus diversos ámbitos invisibilizaciones permanentes de grupos y sujetos sociales, y un entendimiento escaso de la autonomía de las culturas producidas, desde las lógicas de la comprensión social contemporánea resultan sugerentes para la discusión el subrayar tales carencias.

De todas maneras, quedan dudas de por qué considerar a estos personajes ser parte de los orígenes del anticlericalismo del siglo XIX o específicamente ser anticlericales, visible ambas ideas en esta tesis doctoral luego convertido en libro (Klaiber, 1980, pp. 23 y 25). Tal vez por los clamores de reformas eclesiásticas o por las críticas a la curia romana. El aserto, sin embargo, lo mantuvo sin resolver. Aunque luego en La Iglesia en el Perú desaparece esta apreciación y matiza: “...es preciso señalar que los primeros liberales no eran propiamente anticlericales, ni mucho menos antireligiosos" (Klaiber, 1988, p. 98). 
En ese texto establece una división entre el primer liberalismo, al cual se refiere esta nueva apreciación, y el liberalismo de mediados del siglo XIX -de entre 1850 y 1870- al cual sí señala como anticlerical: "El verdadero anticlericalismo aparece a mediados del siglo XIX" (Klaiber, 1988, p. 98). Liberales de segunda generación, enamorados del desarrollo capitalista y del desarrollo de la idea de progreso social, que rechazaron los privilegios sociales y económicos de la Iglesia y su influencia en la sociedad -menciona al tardío Vigil como un representante-, lo cual explicaría las medidas de eliminación de diversos privilegios eclesiásticos, como los fueros eclesiásticos o los diezmos (1856) (Klaiber, 1988, p. 98-99). Hoy día se entiende que estas reformas económicas y jurídicas se plantearon, si bien es cierto en el ánimo de profundizar el desarrollo capitalista y la lógica institucional liberal, también para ampliar las prácticas clientelistas burocráticas, siendo estimuladas desde el Estado y desde diversos grupos sociales no en base a una óptica anticlerical sino más bien dentro de una prolongación del ideario regalista mezclado con los afanes modernizadores de la época (Armas Asín, 2007 y 2010; García Jordán, 1993). Lo cual no quiere decir que abonaran para afianzar en su desarrollo la existencia de ciertos pensadores -algunos influidos por Francisco Bilbao y el pensamiento europeo- que en cierta medida desarrollaron una crítica clerical, aunque encapsulados en esquemas radicales del cual el grueso del corpus político liberal buscó apartarse.

Este interesante cambio de parecer, respecto al carácter anticlerical del primer liberalismo, merece una plausible explicación. Una hipótesis para dicho cambio puede ser el mayor estudio que, sobre el proceso de independencia y la república temprana, le llevó a distanciarse de la influencia que tuvo en sus ideas iniciales los trabajos de Vargas Ugarte y de Tibesar, y sus miradas negativas respecto al liberalismo radical del siglo XIX; autores que veían en las ideas jansenistas y 
galicanas un severo ataque a la Iglesia -su Iglesia, la iglesia romanizada que defendían-, trasmitiendo y compartiendo además el sentir que eclesiásticos diversos del siglo XIX como Mateo Aguilar, Luna Pizarro, y sobre todo las críticas ya conocidas de José Ignacio Moreno, que fueron utilizadas por la historiografía nacional luego para definir como rasgo característico de estos primeros liberales radicales al anticlericalismo (Moreno, 1831). Influencia e impronta institucional y conservadora que se destacaba notoriamente.

\section{Sobre Gonzáles Prada y el anticlericalismo de fines del siglo XIX}

En la Iglesia en el Perú (1988), sin duda un texto producto de la madurez de sus ideas, plantea que el anticlericalismo y afán antirreligioso se afianza a fines de siglo con Manuel Gonzáles Prada, quien fustigó a la Iglesia por impedir el cambio social, y a la religión por ser una forma de superstición, denunciando la explotación del clero a los indígenas (Klaiber, 1988, p. 99).

Pero dirá que formó parte de una generación "desorientada, desilusionada” con el pasado y presente y sin "una visión clara o positiva del futuro" (Klaiber, 1988, p. 111). Por ello remarcó que en sus ideas simplemente dejó “...que otros diseñaran el nuevo mundo por nacer”. Además, consideró que su actitud de denuncia de la religión no fue fruto de un análisis sistémico de ideas, sino del mal recuerdo o ambiente

182 que vivió en su juventud, de una vida familiar con constantes visitas de eclesiásticos a su casa. Allí estuvo la causa de las constantes denuncias a la explotación clerical a los indios de la sierra, pues se descubre al "acusador en busca de chivos expiatorios” (Klaiber, 1988, p. 111).

Estas dos ideas: la causa profunda de su ataque a la religión, como el no plantear una propuesta sólida al futuro, plantea- 
das en 1988, provienen de su tesis doctoral.

En el capítulo segundo de ese anterior texto (1980), contextualiza que el pensamiento occidental cambió mucho para fines del siglo XIX e inicios del siguiente, y Gonzáles Prada encarnó ese cambio. Aunque solitario en sus ideas y propuestas, crítico del sistema económico y político de su tiempo, también desconfió de muchas instituciones a las cuales se acercó. Superando el pensamiento liberal anterior, ubicó la problemática social en las raíces hondas y no superficiales del país. A diferencia de los otros, cuestionó a las religiones mismas, y por supuesto a sus instituciones, como la Iglesia Católica, a las cuales había que desarraigarlas de la sociedad para ayudar en su liberación. Al hacerlo, sin embargo, Klaiber visualiza lúcidamente -como siempre tratando de entender lo acontecido en función de la realidad presente- que "despejó el camino para una nueva comprensión, más original y más realista" del rol de la religión en la sociedad (Klaiber, 1980, p. 45).

Allí, explorando algunos argumentos para saber de donde proviene su anticlericalismo, es que cree verlo en su infancia plagada de frailes y rezos (Klaiber, 1980, p. 45), que luego marcaría algunos de sus poemas iniciales de juventud. En todo caso, tras la guerra del Pacífico, será parte de la generación del Circulo Literario que conforme un núcleo duro de la crítica estética y política de la posguerra. Luego vendrán sus críticas a través de los discursos y artículos periodísticos al orden político, y su denuncia al drama del indio, atosigado por la trinidad embrutecedora del juez, el indio y el gobernador; así como también su apuesta por el cambio a través de una reforma legalista de corte liberal, que significó la Unión Nacional y su programa laicizador y democratizador radical. Pero tras un viaje a Europa y su regreso en 1898, se alejó de esa experiencia reformista y se ahondó en los contactos con los trabajadores y en un pensamiento anarquista, mezclado 
de positivismo y evolucionismo. Klaiber busca entender el anticlericalismo de este nuevo tiempo en Gonzáles Prada, bajo la influencia de nuevo de Jorge Basadre, a quien sigue de cerca, quien aseveró que era un "apóstata", que denunció el pasado, pero sin ofrecer algo nuevo para el futuro (Klaiber, 1980, p. 51).

Bajo esta perspectiva analiza los poemas donde menciona cuestiones religiosas o espirituales, escritos hasta antes de su muerte, considerando que existió una batalla personal, de un autor marcado por el enojo, la amargura y el resentimiento respecto a Dios (Klaiber, 1980, pp. 52-54). Luego sintetiza sus ideas en materia religiosa, enfatizando como Gonzáles Prada, en nombre del progreso y el desarrollo científico, denunció a la religión y a la Iglesia católica. A la primera porque la consideró posterior a la moral y a la segunda por ser hija de las circunstancias históricas. Aspiró a una liberación de los hombres de ellas, pues impedían el avance científico y social, aunque valoró el protestantismo, por haber dado limitadamente alguna respuesta a las necesidades humanas. Específicamente, denunció como la Iglesia no solo perpetuó los poderes existentes sino también llenó de fanatismo a las masas, en particular a las mujeres, impidiendo un desarrollo educativo integral.

Pero, así como había que oponerse a las instituciones como la Iglesia y el Estado, había que depositar una plena confianza en el individuo y su moral. Y superar las visiones del liberalismo y anticlericalismo, e ir a los problemas hondos de la sociedad: no bastaba con denunciar las atrocidades cotidianas del cura mientras no se observarán los crímenes sociales ni las extorsiones políticas que sacudían a la sociedad; no era suficiente derrocar a Dios mientras el mundo se retorcía de dolor (Klaiber, 1980, pp. 54-59). La justicia debía ayudar a destruir esos poderes sociales anclados en el Estado, la Iglesia y el capital; de allí su burla del republicanismo y el cristia- 
nismo, grandes mentiras que ahondaron la explotación. El problema era pues económico y social, y estaba en manos de los indios y el resto de explotados sacudirse a través de su propia liberación (Klaiber, 1980, pp. 59-62).

Klaiber valora positivamente a Gonzáles Prada respecto a los liberales, por detectar en raíces estructurales -aunque hay que enfatizar entre cincuenta o setenta años después de las palabras de Vidaurre o Vigil- los problemas del país. "No podría haber un contraste más grande, por ejemplo, entre el concepto de reforma que tenía Gonzáles Vigil, que consistía en resucitar, pedantescamente, antiguos concilios de la Iglesia, y la condena virulenta que hizo Gonzáles Prada de la explotación clerical de los indios de la sierra" (Klaiber, 1980, p. 63). Aunque reconoce que labró una imagen negativa de la religión y la Iglesia, por la manera como se aproximó, ayudó a verlas dentro de la sociedad y no dentro del ángulo estrecho de una relación Iglesia-Estado (Klaiber, 1980, p. 63).

Sin embargo le critica por no haber valorado la religiosidad popular, que es autónoma de la institucionalidad eclesial, tanto en el campo como en la ciudad. Este desinterés de los anticlericales peruanos por la religiosidad popular le sirve para analizar la rebelión de Huaraz en 1885, en Semana Santa, y comprobar el desconocimiento de las realidades profundas del malestar social popular a fines del siglo XIX que poseían (Klaiber, 1980, pp. 67 -95).

Ciertamente para Gonzáles Prada, y la línea de pensamiento moderno a la que pertenecía, era más que obvia la denuncia al oprobio que esto causaba, al ser la religiosidad popular una extensión de la inoculación en la sociedad de ideas determinadas. En verdad estamos lejos de los aportes de Antonio Gramsci, sobre el catolicismo de las masas y la necesidad de su reconocimiento (Gramsci, 1971: p. 9 y ss.). En todo caso Klaiber cree ver un carácter elitista y poco interés empírico 
por las realidades fácticas, en ese menosprecio de Gonzáles Prada (Klaiber, 1980, p. 64). Una anécdota donde el maestro juguetea sobre la posibilidad de creer o no en Dios, le sirve además para plantear incluso que, en el fondo, era un creyente (Klaiber, 1980, p. 66).

Así pues, aunque le reconoce a Gonzáles Prada su llamado a reivindicar al indígena, no pasó para Klaiber de un gesto romántico y literario dirigido a las elites cultas. Una actitud compartida con muchos de los intelectuales del siglo, aunado a su profundo racismo, cuestión esta última que lo subraya claramente en su libro de 1988.

\section{Masones e indigenistas: otros acercamientos}

También tuvo el padre Klaiber otros acercamientos a diversos grupos o personas, consideradas anticlericales, aunque solo los menciona de paso, dejando para el futuro su desarrollo. Así, anotó la importancia de la masonería en el anticlericalismo peruano, pues tanto el Supremo Consejo como la Gran Logia del Perú cobijaron a figuras como Christian Dam o Carlos G. Amézaga. Recordó el fuerte énfasis anticlerical de la masonería, particularmente en el contexto de conflictos con la Iglesia, como la expulsión de los jesuitas en 1886 (Klaiber, 1988, p. 113). Esto luego se profundizaría a partir de otros estudios contemporáneos, en consonancia con los desarrollos historiográficos latinoamericanos de fines del siglo XX, en

186 el contexto de los estudios sobre los grupos de modernidad nacientes (Armas Asín, 1998; Chocano 2010; Bastian, 1990; Díaz Patiño, 2016; Gazmuri, 1999; Valdivia 2010).

También mencionó la importancia relativa de diversos pensadores indigenistas, más ligados a la crítica del estado del clero que a una actitud antirreligiosa. Por ejemplo resaltó la novela de Narciso Aréstegui, El Padre Horán (1848), que buscó empoderar la 
visión de los indígenas y sus problemas, y recogió la existencia de la religiosidad popular; continuando la visión de denuncia social del cura y sus atrocidades. Que seguirá en la Trinidad del Indio (1885), obra de José Itolarrares, una sagaz persistencia del realismo liberal de denuncia al clero "buitre", que inmediatamente se consolidaría con Clorinda Matto de Turner y su novela Aves sin nido (1889), donde si bien denunció las atrocidades de los curas de pueblos, persistiendo la imagen de los poderes confabulados contra el indio, también abogó por un verdadero cristianismo humano en los Andes (Klaiber, 1980, pp. 97-104) -la influencia o vínculos protestante de Matto de Turner ayudan a entender esto (Kuhl, 1999)-.

En todo caso valoró esta toma de conciencia de los intelectuales por los indios, rumbo a un indigenismo mas claro, anterior al socialismo. Aunque compartían todavía una visión crítica sobre el clero, sin embargo, supuso un cambio de rumbo al entendimiento del carácter autónomo de la religiosidad popular, que tanto le interesó remarcar (Klaiber, 1980, p. 119).

\section{Conclusión}

En el análisis de las ideas del padre Jeffrey Klaiber S.J. en torno al anticlericalismo peruano, mayormente de raigambre liberal, en el siglo XIX, presente en dos de sus textos más importantes, se muestra su renovado y destacable interés por comprenderlo; pues a pesar de que no fue central en sus intereses, al formar parte de las ideas de ese siglo, mereció su atención ${ }^{2}$.

Del análisis se resalta el concienzudo trabajo sobre las obras de diversos pensadores: Vidaurre, Vigil, Mariátegui, Gonzáles Prada, Matto de Turner, entre otros. También el interés por

2 En el año 2013 recupera las ideas de 1988, en un artículo para un evento académico (Klaiber, 2013). 
una delimitación conceptual del anticlericalismo peruano. Igualmente hemos apreciado que, al estudiar su relación con la religión, resaltó los aspectos del cambio social y la religiosidad popular, aunque mostró allí algunas dificultades, desde nuestra perspectiva debido a la impronta eclesial y académica que le rodeó, que le llevó incluso a una ruptura posterior sobre la apreciación del fenómeno. Hoy día, la problemática del anticlericalismo se le busca estudiar en bases más amplias, entendiéndola no solo como una crítica al clero e institución en general, en un momento específico, sino también como un pensamiento que no buscó necesariamente su sustitución o eliminación, sino a veces simplemente un cambio en sus relaciones sociales (Di Stefano, 2010, pp. 11-13). En ese sentido, pudo llegar a ser una forma diferente de ser católico frente al discurso y práctica hegemónicos.

Este encuentro teórico del padre Klaiber con la problemática debe ser visto como expresión de una lucha en el plano historiográfico frente a una tradición que, aunque efectivista en señalar de anticlericales a los pensadores seńalados, les negaba además la fe y la creencia. Buscó distanciarse de ellos, resultando a la larga en una invitación a profundizar en el estudio de la temática. Lo cual, visto en perspectiva, obligó -fue siempre su interés personal- y obliga a la historiografía local sobre el campo religioso a un mejor desarrollo de lo que anteriormente hubiera tenido. Él mismo fue la prueba viviente de superar el entrampe y mirar el siglo XIX de manera diferente, al hacer preguntas contemporáneas y mostrar un presentismo constante en su quehacer.

Recibido: 10 de enero de 2020

Aprobado: 28 de febrero de 2020 


\section{Referencias citadas}

ALBERIGO, G. (ed.)

(2004) Historia de los concilios ecuménicos. Salamanca: Sígueme. Segunda edición.

ARMAS ASÍN, F.

Liberales, Protestantes y Masones. Modernidad y Tolerancia Religiosa. Perú Siglo XIX. Lima: Pontificia Universidad Católica del Perú y Centro Bartolomé de Las Casas.

(2007) Iglesia, Bienes y rentas. Secularización liberal y reorganización patrimonial en Lima (1820-1950). Lima: Instituto de Estudios Peruanos e Instituto RivaAgüero PUCP.

(2010) Patrimonio divino y capitalismo criollo. El proceso desamortizador de censos eclesiásticos en el Perú. Lima: Red para el Desarrollo de la Ciencias Sociales - Instituto Riva-Agüero PUCP - Fundación M.J. Bustamante de la Fuente.

AUBERT, Raphaël et al.

(1984) Nueva Historia de la Iglesia. Tomos IV y V. Madrid: Ediciones Cristiandad. Segunda edición.

BADA ELÍAS, Joan

(2002) Clericalismo y anticlericalismo. Madrid: BAC.

BASTIAN, Jean Pierre, Comp.

(1990) Protestantes, liberales y francmasones. Sociedades de ideas y modernidad en América Latina. México: FCE.

CÁRDENAS, Elisa

(2007) Hacia una historia comparada de la secularización en América Latina, en Guillermo Palacios (Coord.). Ensayos sobre la nueva historia política en América Latina, Siglo XIX. México: El Colegio de México. 
CHOCANO, Magdalena

(2010) Lima masónica. Las logias masónicas y su progreso en el medio urbano a fines del siglo XIX, Revista de Indias, 70-249, 409-444.

DÍAZ PATIÑO, Gabriela

(2016) Católicos, liberales y protestantes: el debate por las imágenes religiosas en la formación de la cultura nacional (1848-1908). México: El Colegio de México.

DE ROUX, Rodolfo

(2014) La romanización de la Iglesia católica en América Latina. Una estrategia de larga duración. Pro-Posiçóes V, 25-1, 31-54.

DI STEFANO, Roberto

(2010) Ovejas Negras. Historia de los anticlericales argentinos. Buenos Aires: Sudamericana.

GAZMURI, Cristián

(1999) El 48 chileno. Igualitarios, reformistas, radicales, masones y bomberos. Santiago: Editorial Universitaria.

GARCÍA JORDÁN, Pilar

(1993) Iglesia y Poder en el Perú contemporáneo 1821-1919. Cuzco: Centro Bartolomé de las Casas.

GRAMSCI, Antonio

(1971) El materialismo histórico y la Filosofía de Benedetto Croce. Buenos Aires: Ediciones Nueva Visión.

KLAIBER, Jeffrey

(1980) Religión y Revolución en el Perú, 1824-1976. Lima: Universidad del Pacífico.

La Iglesia en el Perú. Lima: Pontificia Universidad Católica del Perú

(2013) El Perú: regalistas, modernizantes y apóstatas. En Roberto Di Stefano - José Zanca (comps.), Pasiones 
Anticlericales. Un recorrido iberoamericano. Buenos Aires: Universidad Nacional de Quilmes, pp. 171192.

KUHL, Paul E.

(1989) Posibles aliados: metodistas y francmasones en la lucha por la libertad de cultos en el Perú, Cristianismo y Sociedad XXVII-1, 45-58.

LORTZ, Joseph

(2003) Historia de la Iglesia. Tomo II. Madrid: Ediciones Cristiandad.

MARTÍNEZ, Ignacio

(2014) Circulación de noticias e ideas ultramontanas en el Río de la Plata tras la instalación de la primera nunciatura en la América Ibérica (1830-1842), Historia Critica 52, enero-abril, 73-97.

MAURO, Diego e Ignacio MARTÍNEZ

(2015) Secularización, Iglesia y politica en Argentina. Balance teórico y sintesis histórica. Rosario: Universidad Nacional de Rosario.

MORENO, José Ignacio

(1831) Ensayo sobre la supremacía del Papa, especialmente con respecto a la institución de los obispos. Lima: Imprenta de José Masías.

RÉMOND, René

(1983) Anticlericalism: Some Reflections by Way of Introduction, European Studies Review, 13, 121-126. http://dx.doi.org/10.1177/026569148301300201

(2001) Religion et Societé en Europe. La sécularisation aux XIXe et XXe siécles. 1780-2000. París: Éditions du Seuil. 
TSCHANNEN, Olivier

(2001) Conclusion. La réévaluation de la théorie de la sécularisation par la perspectiva comparatiste Europe latine-Amérique latina. En Jean Pierre Bastian (dir.), La modernité religieuse en perspective comparée. Europe latine - Amérique latine. París: Khartala, pp. 307318.

TIBESAR, Antonine

(1982) The Suppression of the Religious Orders in Peru, 1826-1830, or the King Versus the Perivian Friars: The King Won, The Americas, XXXIX, 205-239.

VARGAS UGARTE, Rubén

(1962) Historia de la Iglesia en el Perú. Tomo V. Burgos: Aldecoa.

VALDIVIA, Maria Inés

(2010) El Liberalismo social en el Perú. Masones, bomberos, librepensadores y anarquistas durante el siglo XIX. Lima: Asamblea Nacional de Rectores. 